\title{
Association of Circulating IgE and CML levels With in-Stent Restenosis After Drug-Eluting Stent Implantation in Type 2 Diabetic Patients With Stable Coronary Artery Disease
}

Jing Meng Liu

Shanghai Jiao Tong University Medical School Affiliated Ruijin Hospital Qiu Jing Chen

Shanghai Jiao Tong University Medical School Affiliated Ruijin Hospital Lin Lu

Shanghai Jiao Tong University Medical School Affiliated Ruijin Hospital Qi Jin

Shanghai Jiao Tong University Medical School Affiliated Ruijin Hospital Yang Yang Bao

Shanghai Jiao Tong University Medical School Affiliated Ruijin Hospital

Tian You Ling

Shanghai Jiao Tong University Medical School Affiliated Ruijin Hospital

Chang Jian Lin

Shanghai Jiao Tong University Medical School Affiliated Ruijin Hospital

\section{Feng Hua Ding}

Shanghai Jiao Tong University Medical School Affiliated Ruijin Hospital

Xiao Qun Wang

Shanghai Jiao Tong University Medical School Affiliated Ruijin Hospital

\section{Wei Feng Shen}

Shanghai Jiao Tong University Medical School Affiliated Ruijin Hospital

\section{Ying Shen}

Shanghai Jiao Tong University Medical School Affiliated Ruijin Hospital

Yang Dai ( $\nabla$ yutongwushe@163.com )

Shanghai Jiao Tong University Medical School Affiliated Ruijin Hospital

\section{Li Qun Wu}

Shanghai Jiao Tong University Medical School Affiliated Ruijin Hospital 
Keywords: Immunoglobulin E, Nع-carboxymethyl-lysine, In-stent restenosis, Diabetes, Percutaneous coronary intervention

Posted Date: September 30th, 2021

DOI: https://doi.org/10.21203/rs.3.rs-934247/v1

License: (1) This work is licensed under a Creative Commons Attribution 4.0 International License. Read Full License 


\section{Abstract}

Background: We investigated whether serum levels of immunoglobin (Ig) $\mathrm{E}$ and $\mathrm{N} \varepsilon$-carboxymethyl-lysine $(\mathrm{CML})$ are related to in-stent restenosis (ISR) in patients with stable coronary artery disease and type 2 diabetes mellitus (T2DM).

Methods: Serum levels of IgE and CML were measured in 416 stable angina patients with T2DM who received angiographic follow-up 12 months after percutaneous coronary intervention (PCI) with thirdgeneration drug-eluting stent (DES) implantation for de novo lesions. Multivariate logistic regression analysis was performed to assess the association between IgE or CML and ISR. In mice models, femoral artery injury was induced in mice receiving albumin or glycated albumin injection, and immunofluorescence staining of the injured artery segment was performed 4 weeks later using $\mathrm{CML}$ and $\lg$ E antibodies.

Results: Both IgE and CML levels were higher in patients with ISR ( $n=196)$ compared with non-ISR patients $(n=220)$. The rate of ISR increased stepwise with increasing tertiles of IgE and CML levels, and IgE correlated significantly with CML. After adjusting for potential confounders, IgE and CML levels remained independently associated with ISR. IgE and CML levels improved the predictive capability of traditional risk factors for ISR, and there existed an interaction between IgE and CML in relation to ISR (P for interaction $<0.01$ ). In mice models, glycated albumin induced increased CML and IgE infiltration in the injured femoral artery segment which was associated with a higher degree of neointimal hyperplasia and luminal stenosis.

Conclusion: Elevated circulating IgE and CML levels confer an increased risk for ISR after DES-based PCI in type 2 diabetic patients with stable coronary artery disease.

\section{Background}

Despite widespread use of drug-eluting stents (DES), in-stent restenosis (ISR) remains a significant clinical problem after percutaneous coronary intervention (PCI) [1], occurring in $3-20 \%$ of patients after DES implantation $[2,3]$. The prevalence of ISR is even higher in patients with type 2 diabetes mellitus (T2DM), which causes particular concern since diabetic population is growing and these patients often have more severe and diffuse coronary artery disease requiring DES-based revascularization [4]. The mechanism of ISR in type 2 diabetic patients remains incompletely elucidated, but is likely to be multifactorial. Apart from mechanical and technical factors as well as patient- and operator-related conditions, certain biochemical abnormalities and inflammatory cytokines induced by diabetes have been documented to exaggerate neointimal hyperplasia and to promote ISR $[1,5,6]$.

Advanced glycation end products (AGEs), which form more abundantly during T2DM as a consequence of chronic hyperglycemia, are extensively distributed in the diabetic vasculature. Mounting evidence has indicated that AGEs play a key role in cell signal to accelerate vasculopathy in diabetes. For example, they react with receptor for AGEs (RAGE) to increase oxidative stress, expression of transforming factor- $\beta$ and 
extracellular matrix accumulation [7]. Elevated AGEs have been suggested as a risk factor for post-PCI restenosis as well as coronary artery disease progression in type 2 diabetic patients[7, 8]. $\mathrm{N} \varepsilon$ carboxymethyl-lysine (CML), a major isoform of AGEs, contributes to endothelial dysfunction in diabetes and is associated with cardiovascular mortality [9-11]. Nevertheless, the relationship between CML and ISR remains unclear.

Immunoglobin (Ig) E, despite its lowest abundance in vivo, exerts a crucial effect in mediating type I hypersensitivity both systematically and locally and defending against pathogens as the first line[12]. Previous studies have demonstrated that elevated IgE level is most common in allergy, and interestingly, the risk of cardiovascular diseases such as acute myocardial infarction, heart failure, atrial fibrillation, and peripheral vascular disease is increased in patients with allergic disorders [13-16]. Recent data revealed that IgE promotes coronary atherosclerosis [17], participates in abdominal aortic aneurysm formation[18] and coronary artery spasm, independent of atheromatous disease[19]. Likewise, elevated IgE level in serum has been shown to correlate with multivessel disease and contribute to discriminating coronary artery disease severity [20].

Although formation of AGEs has been reported to correlate with immunological and allergic disorders such as asthma and arthritis[21], the exact role of allergic inflammation in both pathogenesis of coronary artery disease and occurrence of adverse events following stent implantation just starts to be noticed in recent years [22]. In addition, knowledge regarding the interaction between IgE and CML on ISR is still scanty. In this study, we sought to examine if circulating levels of IgE and CML are associated with ISR in patients with T2DM after PCl with DES implantation. We also assayed serum IgE and CML levels and performed immunofluorescence staining of injured femoral artery in a high-fat diet/streptozotocin (STZ)induced diabetic mouse model.

\section{Methods}

This study was approved by the ethics committee of Ruijin Hospital, Shanghai Jiao Tong University School of Medicine, and conducted according to the Declaration of Helsinki. Written informed consent was obtained from all participants.

\section{Clinical cohort}

A total of 606 consecutive patients with T2DM who received follow-up coronary angiography around 12 months after DES-based PCl of de novo lesions in native coronary artery from January 2017 to December 2020 were recruited from the database of Shanghai Ruijin Hospital PCI Outcome Program[23]. This program utilizes clinical and angiographic information for various cardiovascular diseases to estimate risk-adjusted outcomes. Data on demographics, clinical characteristics and angiographic features, left ventricular function determined by two-dimensional echocardiography according to modified Simpson's rule, and in-hospital management were collected retrospectively, whereas outcomes during follow-up were identified prospectively. For the purpose of this study and to avoid confounding serum data, we excluded patients with acute coronary syndrome $(n=133)$, familial hypercholesterolemia $(n=5)$, malignant tumor $(n$ 
$=6)$, renal failure requiring hemodialysis $(n=4)$ or prior coronary bypass grafting $(n=27)$. Patients with history of asthma $(n=5)$, autoimmune disease $(n=4)$, and rheumatic heart disease $(n=6)$ were also excluded. Thus, the remaining 416 patients were eligible and categorized in the final analysis (Figure 1).

The diagnosis of T2DM was made according to the criteria of American Diabetes Association [symptoms of diabetes with casual plasma glucose concentration $\geq 200 \mathrm{mg} / \mathrm{dL}(11.1 \mathrm{mmol} / \mathrm{L})$ or fasting plasma glucose $\geq 126 \mathrm{mg} / \mathrm{dL}(7.0 \mathrm{mmol} / \mathrm{L}), 2 \mathrm{~h}$ postprandial glucose $\geq 200 \mathrm{mg} / \mathrm{dL}(11.1 \mathrm{mmol} / \mathrm{L})$ during an oral glucose tolerance test, and currently or previously treated with insulin and/or oral hypoglycemic agents] [24]. Hypertension was diagnosed according to seventh report of the Joint National Committee on prevention, detection, evaluation, and treatment of high blood pressure (JNC 7)[25]. Hyperlipidemia was defined according to a guideline on the management of blood cholesterol[26].

\section{Coronary angiography and quantitative analysis}

Coronary angiography and $\mathrm{PCl}$ were performed through radial or femoral approach using standard methods. All lesions were stented with a normal-to-normal technique, usually including 5-mm- long, angiographically normal segments proximal and distal to the lesion. The third-generation DES was applied to all patients, but the choice of stent type and technique of deployment were left for the discretion of the operators. A plurality of matching angiographic images was obtained after intracoronary nitrate injection for each patient. All patients were encouraged to take guideline-recommended medications after the procedure.

End-diastolic frames from both baseline and follow-up angiograms were selected with identical angulations that best showed the stenosis at its most severe degree with minimal foreshortening and branch overlap[27]. Quantitative coronary analysis (QCA) of baseline and follow-up angiograms was made using the Cardiovascular Measurement System version 3.0 software (Terra, GE, USA) by two experienced cardiologists, who were blinded to patients' clinical information and biochemical measurements $[28,29]$. Briefly, the outer diameter of contrast-filled catheter was used for calibration to determine absolute measurements in millimeters. Lesion length was measured as the distance from the proximal to distal shoulder. A value of $0 \mathrm{~mm}$ was assigned for minimal lumen diameter in the case of total occlusion at baseline. ISR was defined as recurrence of luminal diameter stenosis of $>50 \%$ within the stent or in the 5-mm proximal or distal segments adjacent to the stent at follow-up angiography [28, 29]. For patients with multiple coronary lesions, the most severe restenotic lesion at follow-up was included in the analysis.

\section{Biochemical assessments}

Peripheral venous blood samples were obtained at the day of angiography after an overnight fasting. To avoid a diurnal variation in IgE concentration and dramatic fasting interval effects, all blood samples were obtained at 8:00 am. Serum levels of glucose, blood urea nitrogen, uric acid, creatinine, and lipid profiles, including triglyceride, total cholesterol, low-density lipoprotein (LDL) cholesterol, high-density lipoprotein (HDL) cholesterol, lipoprotein (a), apolipoprotein A-I and apolipoprotein B were measured 
using standard laboratory techniques on a HITACHI 912 Analyzer (Roche Diagnostics, Germany). Blood concentration of glycosylated hemoglobin ( $\mathrm{HbA} 1 \mathrm{c})$ was measured using ion-exchange high performance liquid chromatography with Bio-rad Variant Hemoglobin Testing System (Bio-Rad Laboratories, USA). Serum levels of high-sensitivity C-reactive protein (hsCRP) were determined by ELISA (Biocheck Laboratories, Toledo, $\mathrm{OH}, \mathrm{USA}$ ). The estimated glomerular filtration rate (eGFR) was calculated using the Chronic Kidney Disease Epidemiology Collaboration equation [30].

Serum levels of IgE and CML were determined by enzyme-linked immunosorbent assay (ELISA) according to the manufacturer's protocols (BMS2097, eBioscience; STA-816, Cell BioLabs). The average inter-assay coefficient of variance (CV) was $6.2 \%$ and $5.8 \%$ for IgE and CML, respectively, and the average intra-assay CV was $6.6 \%$ or $7.2 \%$ for IgE or CML, respectively.

\section{Diabetic mouse model}

Animal experiments were approved by Hospital Animal Care Committee and complied with Guide for the Care and Use of Laboratory Animals by the National Institutes of Health. 6-8 weeks old C57BL/6J male mice were housed in a pathogen-free environment and received intraperitoneal injections of albumin

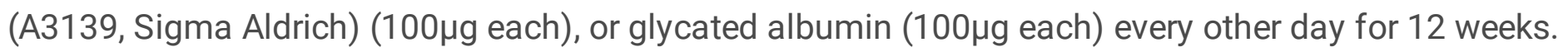
The glycated albumin was prepared through a glycation process[8]. Then, femoral artery injury was induced with a wire as previously described [31]. Serum was collected for analysis of CML and IgE 4 weeks later using ELISA kit (STA-816, Cell BioLabs; E99-115, Bethyl Laboratories) and injured femoral artery was harvested for hematoxylin and eosin staining and immunofluorescence staining using $\mathrm{CML}$ and IgE antibodies (ab27684, Abcam; 553416, BD Biosciences,).

\section{Statistical analysis}

All statistical analyses were performed with SPSS 26.0 (IBM, Armonk, New York) and R Programming Language 4.0.2. Continuous variables are expressed as mean \pm standard deviation (SD) if data were normally distributed, or as median (25th-75th percentile) otherwise, and categorical variables are summarized as frequencies (percentages). IgE and CML levels were presented both as an original skewedly-distributed variable and a $\log _{2}$ transformed normally distributed variable. Continuous variables were compared between two groups using student's t-test or Mann-Whitney U test. For categorical variables, differences between groups were evaluated with chi-square test. Pearson's and Spearman's correlation tests were used to assess the relation between IgE and CML. Logistic regression models were applied to detect the relationship between ISR and serum IgE or CML level. IgE or CML was analyzed as a continuous variable with log- transformation, as an ordinal variable, and as a categorical variable divided into tertiles. Odds ratios (OR) were calculated with unadjusted, adjusted for age, sex, body mass index, smoking, dyslipidemia, hypertension (model 1), and further adjusted by adding $\mathrm{HbA} 1 \mathrm{c}$, left ventricular ejection fraction, statin use, number of diseased vessels, B2/C lesion, bifurcation, chronic total occlusion, and stent diameter (model 2). Receiver-operating characteristic (ROC) curves were plotted to determine the power of IgE and CML for detecting ISR, and the $\mathrm{C}$ statistics was compared using Delong method. 
Category-free net reclassification improvement (NRI) and integrated discrimination improvement (IDI) were calculated to assess the added value in reclassification of the patients. The 2-sided $P$ value $<0.05$ was considered statistically significant.

\section{Results}

\section{Baseline clinical characteristics}

In this clinical cohort, ISR and non-ISR were detected in 196 and 220 patients, respectively. Patients with or without ISR did not differ with respect to age, gender distribution, body mass index, risk factors for coronary artery disease and renal function. Blood concentrations of HbA1c and hsCRP were higher whereas left ventricular ejection fraction and statin use were lower in ISR patients. Despite similar degree of coronary stenosis intervened and average number and length of stents implanted, patients with ISR received smaller stents, and had higher percentages of circumflex or right coronary artery lesion, multivessel disease, and complex lesion morphology (Table 1).

\section{IgE and CML levels with ISR}

Serum levels of IgE and CML were higher in ISR group compared with non-ISR group [IgE: 187.10 (63.75489.65) vs 80.25 (30.65-202.50), P<0.001; CML: 203.26 (164.50-266.84) vs 174.26 (130.85-215.56), $P<0.001]$. There was a stepwise increase in incidence of ISR from the lowest tertile to the highest tertile of Ig $E$ or $C M L$ (all $P$ for trend $<0.001$ ) (Figure 2). Serum IgE correlated positively with CML levels (all patients: $r=0.331$, $P<0.001$; ISR group: $r=0.433$, $P<0.001$; non-ISR group: $r=0.153, P=0.023$ ), even after adjusting for confounding factors (Table 2). Logistic regression models were constructed to confirm the association between ISR and IgE or CML level in various subgroups (Figure 3). In multivariable analysis, both serum IgE and CML levels remained independent factors for ISR in patients with T2DM after adjusting for age, sex, body mass index, smoking, dyslipidemia, hypertension, HbA1c, left ventricular ejection fraction, stain use, number of diseased vessel, class B2/C lesion, bifurcation, chronic total occlusion, and stent diameter. The result patterns were similar when serum IgE or CML level was used as a standardized continuous variable with log-transformation and as an ordinal or categorical variable (Table 3).

ROC curves showed that addition of IgE or CML to the basic clinical model significantly improved diagnostic performance for ISR in patients with T2DM [area under the curve (AUC): 0.759 (0.713-0.804) or 0.748 (0.701-0.794) vs 0.705 (0.655-0.755), all $P<0.01$ ] (Figure 4). Likewise, compared with the basic clinical model, the inclusion IgE or CML had significant improvement in reclassification as assessed by the categorical NRI [0.120 (0.047-0.194); 0.099 (0.034-0.163), respectively] and IDI [0.074 (0.049-0.010); 0.062 (0.038-0.086), respectively] (Table 4). More importantly, there was a significant interaction between $\operatorname{lgE}$ and $\mathrm{CML}$ in relation to ISR ( $P$ for interaction < 0.01). At high tertile of $\operatorname{lgE}(\geq 210.7 \mathrm{ng} / \mathrm{ml})$, patients with high tertile of CML ( $\geq 215.5 \mathrm{ng} / \mathrm{ml}$ ) had a significantly increased risk of ISR compared with those with low tertile of $\mathrm{CML}(\leq 161.5 \mathrm{ng} / \mathrm{ml}$ ) (adjusted OR=6.784, 95\% Cl 2.304-19.969, $\mathrm{P}=0.001$ ) (Figure 5). 


\section{Findings in mice models}

Mice receiving glycated albumin injection exhibited elevated CML and IgE levels in serum and increased $\mathrm{CML}$ and IgE infiltration in the injured femoral artery segment which were associated with a higher degree of neointimal hyperplasia and luminal stenosis (Figure.6).

\section{Discussion}

This study is the first to show that in type 2 diabetic patients with stable coronary artery disease, $\lg E$ correlated positively with CML. Elevated IgE and CML was associated ISR after DES-based PCI, independent of traditional risk factors.

\section{Role of elevated circulating IgE and CML in ISR}

In the bare metal stent era, the stainless-steel struts may act as a foreign body to induce effector cells of hypersensitivity, increasing IgE release and participating in ISR [32,33]. Our study cohort is unique as all patients had stable angina and received third-generation DES which reflects well the current clinical practice. The technology of new DES has been improved dramatically, often consisting of a cobaltchromium alloy platform, an antiproliferative drug (such as everolimus or zotarolimus) and a biodegradable polymer-coating with enhanced biocompatibility [34]. Nevertheless, the stent being an exogenous substance may cause several reactions by promoting proliferation of vascular smooth muscle cells, immune responses and neointima hyperplasia after implantation, leading to ISR and late thrombosis.

The major finding of this study is that serum IgE levels were higher in patients with ISR comparted to nonISR group. Furthermore, the incidence of ISR increased stepwise across the tertiles of serum IgE, and circulating IgE level remained an independent factor for ISR in patients with T2DM after adjusting for potential confounders. These observations jointly support a notion that allergic inflammation to stent contributes, at least partly, to the development of ISR in type 2 diabetic patients after DES-based PCI. Finn et al reported that allergy-mediated inflammation plays a more critical role with DES-related ISR than with bare metal stent-related ISR[35]. Previous studies have shown that IgE is associated with diabetes status and may be an independent risk factor for pre-diabetes and diabetes [36, 37]. IgE induces platelet activation and aggregation [38] and arterial smooth muscle hyperplasia [39], which are essential in the pathophysiology of ISR [40]. More importantly, IgE activates mast cells and basophils by binding to highaffinity receptor FceRI [41], and induces release of preformed inflammatory mediators and de novo synthesis and secretion of cytokines, chemokines, and eicosanoids, which may cause adverse events after stent implantation $[22,42]$. Based on these findings and our results, we speculate that in diabetic patients who had elevated serum IgE, vascular injury resulting from balloon dilatation and stent implantation could increase further IgE levels and activate allergic inflammation and relevant effector cells, potentially facilitating the occurrence of ISR. 
Another finding of this study is that CML, one of the most typical AGEs that have been implicated in diabetes-related complications [7, 9], was correlated with ISR in patients with T2DM. Abundant evidence has demonstrated that production of AGEs is not only a sign of high blood sugar, but also reflects cumulative metabolic burden, oxidative stress and inflammation[43]. AGEs elicit secretion of inflammatory cytokines in basophils which are thought to play a pivotal role in allergic reactions and abundant expression of high-affinity receptors for $\operatorname{lgE}[44,45]$. In the study of food allergy, CML acts as an immunogen by inducing activation and proliferation of various immune cells, and participates in the development of chronic inflammation $[46,47]$. Our results show that IgE correlated positively with $C M L$ and there existed a significant interaction of $\operatorname{lgE}$ and $\mathrm{CML}$ in relation to ISR, suggesting that elevated circulating CML might contribute to activation of granular cells and amplification of inflammation, mediating more local and systemic IgE release and, at the same time, leading to the pathogenesis of ISR in type 2 diabetic patients.

\section{Potential clinical implications}

The findings of the present study are of clinical relevance. Our results imply that measurement of IgE and $\mathrm{CML}$ is useful for evaluating the risk of ISR in patients with T2DM undergoing DES-based PCI. More importantly, aggressive glycemic control and anti-allergic and anti-inflammatory therapy might be mandatory to reduce ISR, especially for individuals with high level of IgE or CML[48]. Further prospective studies with large cohorts are warranted to confirm these issues.

\section{Study limitations}

The present study has several limitations inherited from its retrospective, cross-sectional design for the point of ISR investigation, thereby allowing us to detect association, not to formulate causal link. The sample size in ISR and non-ISR groups was small and all patients were specially selected. Although baseline clinical characteristics and angiographic features were quite homogenously distributed in patients with and without ISR, certain selection biases and unknown confounding factors possibly impacting on IgE and CML could not be excluded. ISR was determined by interpretation of angiography but not through intracoronary imaging (such as intravascular ultrasound), thus we could not provide the details about the degree of ISR. Finally, the relation of serum IgE and CML levels with ISR will be more precisely characterized by serial biochemical measurements.

\section{Conclusions}

This study demonstrates that in patients with T2DM, elevated serum IgE and CML levels confer an increased risk of ISR after DES-based PCI. Novel information as such provides new insight into the pathophysiology of ISR and the management of type 2 diabetic patients with stable coronary artery disease.

\section{Abbreviations}


AGEs: advanced glycation end-products; AUC: area under the curve; CML: Nع-carboxymethyl-lysine; DES: drug-eluting stent; HbA1c: glycosylated hemoglobin; IDI: integrated discrimination improvement; Ig: immunoglobin; ISR: in-stent restenosis; HDL: high-density lipoprotein; LDL: low-density lipoprotein; NRI: net reclassification improvement; OR: odds ratio; PCl: percutaneous coronary intervention; QCA: quantitative coronary analysis; RAGE: receptor for AGEs; ROC: receiver-operating characteristic; SD: standard deviation; T2DM: type 2 diabetes mellitus.

\section{Declarations}

\section{Ethics approval and consent to participate}

The study protocol was approved by the Institutional Review Board of Ruijin Hospital, Shanghai Jiao Tong University School of Medicine. Written informed consent was obtained from all patients, and clinical investigation was conducted according to the principle of the Declaration of Helsinki.

\section{Consent for publication}

All authors consent this manuscript for publication.

\section{Availability of data and materials}

Data generated or analyzed during this study are included in this published article.

\section{Competing interests}

The authors declare that they have no competing interests.

\section{Funding}

This study was supported in part by the Research Foundation of Chinese National Natural Science (81870250, 81970362, 81970293, 81870357).

\section{Authors' contributions}

YD, YS and LQW wrote the article, substantially contributed to discussion of the content, and edited the manuscript. JML, QJC, YYB, TYL, CJL, FHD, XQW performed the experiments and researched data for the article. YD, YS, JML and QJC analyze the data; LL, QJ and WFS substantially contributed to discussion of the content and reviewed the manuscript.

\section{Acknowledgements}

Not applicable.

\section{Author details}


1 Department of cardiovascular medicine, Ruijin Hospital, Shanghai Jiao Tong University School of Medicine, Shanghai 200025, People's Republic of China.

2 Institute of Cardiovascular Diseases, Shanghai Jiao Tong University School of Medicine, 197 Ruijin Road II, Shanghai 200025, People's Republic of China.

Email address: Jing Meng Liu (liujingmeng@163.com); Qiu Jing Chen (cqj40575@rjh.com.cn); Lin Lu (rjlulin1965@163.com); Qi Jin (jinqi127@163.com), Yang Yang Bao (oliverbao@icloud.com), Tian You Ling (Ity0919@hotmail.com); Chang Jian Lin (linchangjian222@126.com); Feng Hua Ding (ruijindfh@126.com); Xiao Qun Wang (xiaoqun_wang@hotmail.com); Wei Feng Shen (rjshenweifeng@126.com); Ying Shen (rjshenying@qq.com); Yang Dai (yutongwushe@163.com); Li Qun Wu (wuliqun89@hotmail.com)

\section{References}

1. Alfonso F, Byrne RA, Rivero F, Kastrati A. Current treatment of in-stent restenosis. J Am Coll Cardiol. 2014;63(24):2659-73.

2. Dangas GD, Claessen BE, Caixeta A, Sanidas EA, Mintz GS, Mehran R. In-stent restenosis in the drugeluting stent era. J Am Coll Cardiol. 2010;56(23):1897-907.

3. Siontis GCM, Stefanini GG, Mavridis D, Siontis KC, Alfonso F, Pérez-Vizcayno MJ, Byrne RA, Kastrati A, Meier B, Salanti G, et al: Percutaneous coronary interventional strategies for treatment of in-stent restenosis: a network meta-analysis. The Lancet 2015, 386(9994):655-664.

4. Bednarska J, Bednarska-Chabowska D, Adamiec-Mroczek J. Coronary artery disease: New Insights into revascularization treatment of diabetic patients. Adv Clin Exp Med. 2017;26(7):1163-7.

5. Cassese S, Byrne RA, Tada T, Pinieck S, Joner M, Ibrahim T, King LA, Fusaro M, Laugwitz KL, Kastrati A. Incidence and predictors of restenosis after coronary stenting in 10004 patients with surveillance angiography. Heart. 2014;100(2):153-9.

6. Shlofmitz E, lantorno M, Waksman R. Restenosis of Drug-Eluting Stents: A New Classification System Based on Disease Mechanism to Guide Treatment and State-of-the-Art Review. Circ Cardiovasc Interv. 2019;12(8):e007023.

7. Goldin A, Beckman JA, Schmidt AM, Creager MA. Advanced glycation end products: sparking the development of diabetic vascular injury. Circulation. 2006;114(6):597-605.

8. Dai Y, Shen Y, Li QR, Ding FH, Wang XQ, Liu HJ, Yan XX, Wang LJ, Yang K, Wang HB, et al. Glycated Apolipoprotein A-IV Induces Atherogenesis in Patients With CAD in Type 2 Diabetes. J Am Coll Cardiol. 2017;70(16):2006-19.

9. Chen Y, Niu W, Chao YC, He Z, Ding R, Wu F, Liang C. Alagebrium targets the miR-27b/TSP-1 signaling pathway to rescue $\mathrm{N}$ (epsilon)-carboxymethyl-lysine-induced endothelial dysfunction. Am J Transl Res. 2019;11(3):1569-80. 
10. Semba RD, Bandinelli S, Sun K, Guralnik JM, Ferrucci L. Plasma carboxymethyl-lysine, an advanced glycation end product, and all-cause and cardiovascular disease mortality in older communitydwelling adults. J Am Geriatr Soc. 2009;57(10):1874-80.

11. Hartog JW, Voors AA, Schalkwijk CG, Scheijen J, Smilde TD, Damman K, Bakker SJ, Smit AJ, van Veldhuisen DJ. Clinical and prognostic value of advanced glycation end-products in chronic heart failure. Eur Heart J. 2007;28(23):2879-85.

12. Wu LC, Zarrin AA. The production and regulation of IgE by the immune system. Nat Rev Immunol. 2014;14(4):247-59.

13. Cepelis A, Brumpton BM, Laugsand LE, Dalen H, Langhammer A, Janszky I, Strand LB. Asthma, asthma control and risk of acute myocardial infarction: HUNT study. Eur J Epidemiol. 2019;34(10):967-77.

14. Carter P, Lagan J, Fortune C, Bhatt DL, Vestbo J, Niven R, Chaudhuri N, Schelbert EB, Potluri R, Miller CA. Association of Cardiovascular Disease With Respiratory Disease. J Am Coll Cardiol. 2019;73(17):2166-77.

15. Iribarren C, Tolstykh IV, Miller MK, Sobel E, Eisner MD. Adult asthma and risk of coronary heart disease, cerebrovascular disease, and heart failure: a prospective study of 2 matched cohorts. Am J Epidemiol. 2012;176(11):1014-24.

16. Liu H, Fu Y, Wang K. Asthma and risk of coronary heart disease: A meta-analysis of cohort studies. Ann Allergy Asthma Immunol. 2017;118(6):689-95.

17. Wang J, Cheng X, Xiang MX, Alanne-Kinnunen M, Wang JA, Chen H, He A, Sun X, Lin Y, Tang TT, et al. IgE stimulates human and mouse arterial cell apoptosis and cytokine expression and promotes atherogenesis in Apoe-/- mice. J Clin Invest. 2011;121(9):3564-77.

18. Wang J, Lindholt JS, Sukhova GK, Shi MA, Xia M, Chen H, Xiang M, He A, Wang Y, Xiong N, et al. IgE actions on CD4 + T cells, mast cells, and macrophages participate in the pathogenesis of experimental abdominal aortic aneurysms. EMBO Mol Med. 2014;6(7):952-69.

19. Kounis NG. Kounis syndrome (allergic angina and allergic myocardial infarction): a natural paradigm? Int J Cardiol. 2006;110(1):7-14.

20. Guo X, Yuan S, Liu Y, Zeng Y, Xie H, Liu Z, Zhang S, Fang Q, Wang J, Shen Z. Serum IgE levels are associated with coronary artery disease severity. Atherosclerosis. 2016;251:355-60.

21. Tochino Y, Kanazawa H, Ichimaru Y, Asai K, Kyoh S, Hirata K. Nepsilon-(carboxymethyl)lysine, a major advanced glycation end product in exhaled breath condensate as a biomarker of small airway involvement in asthma. J Asthma. 2007;44(10):861-6.

22. Niccoli G, Montone RA, Sabato V, Crea F. Role of Allergic Inflammatory Cells in Coronary Artery Disease. Circulation. 2018;138(16):1736-48.

23. Shen Y, Ding FH, Sun JT, Pu LJ, Zhang RY, Zhang Q, Chen QJ, Shen WF, Lu L. Association of elevated apoA-I glycation and reduced HDL-associated paraoxonase1, 3 activity, and their interaction with angiographic severity of coronary artery disease in patients with type 2 diabetes mellitus. Cardiovasc Diabetol. 2015;14:52. 
24. American Diabetes A. 2. Classification and Diagnosis of Diabetes: Standards of Medical Care in Diabetes-2020. Diabetes Care. 2020;43(Suppl 1):14-31.

25. Chobanian AV, Bakris GL, Black HR, Cushman WC, Green LA, Izzo JL Jr, Jones DW, Materson BJ, Oparil S, Wright JT Jr, et al. The Seventh Report of the Joint National Committee on Prevention, Detection, Evaluation, and Treatment of High Blood Pressure: the JNC 7 report. JAMA. 2003;289(19):2560-72.

26. Grundy SM, Stone NJ, Bailey AL, Beam C, Birtcher KK, Blumenthal RS, Braun LT, de Ferranti S, FaiellaTommasino J, Forman DE, et al: 2018 AHA/ACC/AACVPR/AAPA/ABC/ACPM/ADA/AGS/APhA/ASPC/NLA/PCNA Guideline on the Management of Blood Cholesterol: A Report of the American College of Cardiology/American Heart Association Task Force on Clinical Practice Guidelines. Circulation 2019, 139(25):e1082-e1143.

27. Lu L, Jin Pu L, Chen QJ, Wang L, Peng W, Yan X, Zhang Q, Yan Zhang R, Gong PH, Qiu JP, et al. Increased glycated albumin and decreased esRAGE concentrations are associated with in-stent restenosis in Chinese diabetic patients. Clin Chim Acta. 2008;396(1-2):33-7.

28. Yang CD, Shen Y, Lu L, Yang ZK, Hu J, Zhang RY, Shen WF, Ding FH, Wang XQ. Visit-to-visit HbA1C variability is associated with in-stent restenosis in patients with type 2 diabetes after percutaneous coronary intervention. Cardiovasc Diabetol. 2020;19(1):133.

29. Hong SJ, Ahn CM, Kim BK, Ko YG, Hur SH, Yu CW, Lee SJ, Choi CU, Kim JS, Yoon JH, et al. Prospective randomized comparison of clinical and angiographic outcomes between everolimuseluting vs. zotarolimus-eluting stents for treatment of coronary restenosis in drug-eluting stents: intravascular ultrasound volumetric analysis (RESTENT-ISR trial). Eur Heart J. 2016;37(45):3409-18.

30. Levey AS, Stevens LA, Schmid CH, Zhang YL, Castro AF 3rd, Feldman HI, Kusek JW, Eggers P, Van Lente $F$, Greene T, et al. A new equation to estimate glomerular filtration rate. Ann Intern Med. 2009;150(9):604-12.

31. Kessler T, Zhang L, Liu Z, Yin X, Huang Y, Wang Y, Fu Y, Mayr M, Ge Q, Xu Q, et al. ADAMTS-7 inhibits re-endothelialization of injured arteries and promotes vascular remodeling through cleavage of thrombospondin-1. Circulation. 2015;131(13):1191-201.

32. Farb A, Sangiorgi G, Carter AJ, Walley VM, Edwards WD, Schwartz RS, Virmani R. Pathology of acute and chronic coronary stenting in humans. Circulation. 1999;99(1):44-52.

33. Kounis NG, Koniari I, Roumeliotis A, Tsigkas G, Soufras G, Grapsas N, Davlouros P, Hahalis G. Thrombotic responses to coronary stents, bioresorbable scaffolds and the Kounis hypersensitivityassociated acute thrombotic syndrome. J Thorac Dis. 2017;9(4):1155-64.

34. Barros V, Pereira M, Araujo C, Braga P, Azevedo A. Use of drug-eluting versus bare-metal stents after an acute coronary syndrome in Portugal: the EURHOBOP study. Rev Port Cardiol. 2015;34(7-8):44956.

35. Finn AV, Nakazawa G, Joner M, Kolodgie FD, Mont EK, Gold HK, Virmani R. Vascular responses to drug eluting stents: importance of delayed healing. Arterioscler Thromb Vasc Biol. 2007;27(7):150010. 
36. Kim MK, Jeong JS, Han K, Baek KH, Song KH, Kwon HS. House dust mite and Cockroach specific Immunoglobulin E sensitization is associated with diabetes mellitus in the adult Korean population. Sci Rep. 2018;8(1):2614.

37. Wang Z, Zhang H, Shen XH, Jin KL, Ye GF, Qiu W, Qian L, Li B, Zhang YH, Shi GP. Immunoglobulin E and mast cell proteases are potential risk factors of impaired fasting glucose and impaired glucose tolerance in humans. Ann Med. 2013;45(3):220-9.

38. Gresele P, Todisco T, Merante F, Nenci GG. Platelet activation and allergic asthma. N Engl J Med. 1982;306(9):549.

39. Morley J, Sanjar S, Page CP. The platelet in asthma. Lancet. 1984;2(8412):1142-4.

40. Wang Z, Liu C, Fang H. Blood Cell Parameters and Predicting Coronary In-Stent Restenosis. Angiology. 2019;70(8):711-8.

41. Kanagaratham C, El Ansari YS, Lewis OL, Oettgen HC. IgE and IgG Antibodies as Regulators of Mast Cell and Basophil Functions in Food Allergy. Front Immunol. 2020;11:603050.

42. Rivera J, Gilfillan AM. Molecular regulation of mast cell activation. J Allergy Clin Immunol. 2006;117(6):1214-25. quiz 1226.

43. Moldogazieva NT, Mokhosoev IM, Mel'nikova TI, Porozov YB, Terentiev AA. Oxidative Stress and Advanced Lipoxidation and Glycation End Products (ALEs and AGEs) in Aging and Age-Related Diseases. Oxid Med Cell Longev. 2019;2019:3085756.

44. Han K, Suzukawa M, Yamaguchi M, Sugimoto N, Nakase Y, Toda T, Nagase H, Ohta K. The in vitro effects of advanced glycation end products on basophil functions. Int Arch Allergy Immunol. 2011;155(Suppl 1):64-70.

45. Sohouli MH, Fatahi S, Sharifi-Zahabi E, Santos HO, Tripathi N, Lari A, Pourrajab B, Kord-Varkaneh H, Gaman MA, Shidfar F. The Impact of Low Advanced Glycation End Products Diet on Metabolic Risk Factors: A Systematic Review and Meta-Analysis of Randomized Controlled Trials. Adv Nutr. 2021;12(3):766-76.

46. Toda M, Hellwig M, Henle T, Vieths S. Influence of the Maillard Reaction on the Allergenicity of Food Proteins and the Development of Allergic Inflammation. Curr Allergy Asthma Rep. 2019;19(1):4.

47. Gupta RK, Gupta K, Sharma A, Das M, Ansari IA, Dwivedi PD. Maillard reaction in food allergy: Pros and cons. Crit Rev Food Sci Nutr. 2018;58(2):208-26.

48. Eriksson L, Erdogdu O, Nystrom T, Zhang Q, Sjoholm A. Effects of some anti-diabetic and cardioprotective agents on proliferation and apoptosis of human coronary artery endothelial cells. Cardiovasc Diabetol. 2012;11:27.

\section{Tables}

Table 1 Baseline characteristics in patients with T2DM 
Non-ISR $(n=220)$

\begin{tabular}{l} 
Male, $\mathrm{n}(\%)$ \\
Age, $\mathrm{y}$ \\
Body mass index, $\mathrm{kg} / \mathrm{m}^{2}$ \\
\hline Smoking, $\mathrm{n}(\%)$ \\
Hypertension, $\mathrm{n}(\%)$ \\
Systolic blood pressure, $\mathrm{mm} \mathrm{Hg}$ \\
Diastolic blood pressure, $\mathrm{mm} \mathrm{Hg}$ \\
Dyslipidemia, $\mathrm{n}(\%)$
\end{tabular}

Serum creatinine, $\mu \mathrm{mol} / \mathrm{L}$

eGFR, $\mathrm{mL} / \mathrm{min}$ per $1.73 \mathrm{~m}^{2}$

$\mathrm{HbA1c}, \%$

Fasting blood glucose, $\mathrm{mmol} / \mathrm{L}$

Triglyceride, $\mathrm{mmol} / \mathrm{L}$

Total cholesterol, $\mathrm{mmol} / \mathrm{L}$

HDL cholesterol, mmol/L

LDL cholesterol, $\mathrm{mmol} / \mathrm{L}$

hsCRP, mg/L

$\lg \mathrm{E}, \mathrm{ng} / \mathrm{ml}$

$\mathrm{CML}, \mathrm{ng} / \mathrm{ml}$

Ejection fraction, \%

\section{Medication, n (\%)}

Dual antiplatelet therapy

ACEI/ARB

$\beta$-Blockers

Statins

\section{Diseased vessel, $n$ (\%)}

Left main

Left anterior descending

168 (76.4)

$66.53 \pm 9.43$

$25.50 \pm 3.42$

$63(28.6)$

169 (76.8)

$137.85 \pm 20.40$

$74.41 \pm 12.58$

25 (11.4)

$80.00 \pm 17.26$

$7.33 \pm 1.35$

$7.15 \pm 2.28$

$1.75 \pm 1.72$

$3.62 \pm 1.01$

$1.09 \pm 0.27$

$2.04 \pm 0.80$

0.94 (0.41-2.24)

$62.46 \pm 8.89$

209 (95.0)

$146(66.4)$

183 (83.2)

217 (98.6)

$11(5.0)$

157 (71.4)
80.00 (70.25-93.00)

80.25 (30.65-202.50)

174.26 (130.85-215.56)

$19(9.7)$

0.065
ISR ( $\mathrm{n}=196)$

$P$ Value

143 (73.0)

0.425

$67.59 \pm 8.82$

0.241

$25.10 \pm 3.46$

0.235

59 (30.1)

0.743

$160(81.6)$

0.228

$140.26 \pm 22.04$

0.248

$75.43 \pm 14.69$

0.448

$20(10.2)$

0.704

82.50 (68.00-99.75)

0.518

$78.77 \pm 33.05$

0.640

$7.64 \pm 1.35$

0.020

$7.66 \pm 2.94$

0.050

$1.64 \pm 1.16$

0.442

$3.59 \pm 1.03$

0.823

$1.04 \pm 0.26$

0.054

$2.02 \pm 0.85$

0.877

$1.15(0.52-4.59)$

0.021

$187.10(63.75-489.65) \quad<0.001$

$203.26(164.50-266.84)<0.001$

$60.34 \pm 10.54$

0.028

185 (94.4)

0.781

132 (67.3)

0.832

159 (81.1)

0.584

184 (93.9)

0.009
0.118 


\begin{tabular}{|c|c|c|c|c|c|}
\hline Left circumflex & $98(44.5)$ & & $115(58.7)$ & & 0.004 \\
\hline Right coronary artery & $108(49.1)$ & & $138(70.4)$ & & $<0.001$ \\
\hline \multicolumn{6}{|l|}{ Severity of CAD, n (\%) } \\
\hline 1-vessel & $114(51.8)$ & & $56(28.6)$ & & $<0.001$ \\
\hline 2-vessel & $69(31.4)$ & & $70(35.7)$ & & 0.348 \\
\hline 3-vessel & $37(16.8)$ & & $70(35.7)$ & & $<0.001$ \\
\hline Multivessel disease & $106(48.2)$ & & $140(71.4)$ & & $<0.001$ \\
\hline \multicolumn{6}{|l|}{ Lesion characteristics } \\
\hline Class B2/C lesion, n (\%) & $135(61.4)$ & $145(74.0)$ & & 0.006 & \\
\hline Bifurcation lesion, n (\%) & $54(24.5)$ & $71(36.2)$ & & 0.009 & \\
\hline Chronic total occlusion, n (\%) & $23(10.5)$ & $36(18.4)$ & & 0.021 & \\
\hline Pre-PCI stenosis, \% & $85.86 \pm 6.29$ & $86.81 \pm 8.20$ & & 0.189 & \\
\hline Average number of stents, $\mathrm{n}$ & $1.51 \pm 0.71$ & $1.63 \pm 0.73$ & & 0.106 & \\
\hline Stent diameter, $\mathrm{mm}$ & $2.98 \pm 0.40$ & $2.84 \pm 0.35$ & & $<0.001$ & \\
\hline Stent length, mm & $28.52 \pm 2.57$ & $28.13 \pm 4.94$ & & 0.322 & \\
\hline
\end{tabular}

T2DM: Type 2 diabetes mellitus; ISR: in-stent restenosis; eGFR: estimated glomerular filtration rate; HbA1c: glycated hemoglobin A1c; HDL: high-density lipoprotein; LDL: low-density lipoprotein; hsCRP: high-sensitivity $\mathrm{C}$ reactive protein; IgE: immunoglobulin E; CML: $\mathrm{N} \varepsilon$-carboxymethyl-lysine; ACEI/ARB: angiotensin-converting enzyme inhibitor/angiotensin receptor blocker; PCl: percutaneous coronary intervention

Table 2 Correlation between CML and IgE in patients with T2DM

\begin{tabular}{|lllll|}
\hline & Unadjusted $r$ & Unadjusted $P$ & *Adjusted $r$ & *Adjusted $P$ \\
\hline All & 0.331 & $<0.001$ & 0.324 & $<0.001$ \\
\hline ISR & 0.433 & $<0.001$ & 0.441 & $<0.001$ \\
\hline Non-ISR & 0.153 & 0.023 & 0.169 & 0.014 \\
\hline
\end{tabular}

* adjusted for age, sex, body mass index, smoking, dyslipidemia, hypertension, HbA1c, LVEF, statin use, number of diseased vessel, class B2/C lesion, bifurcation lesion, CTO lesion, stent diameter. T2DM: type 2 diabetes mellitus; ISR: in-stent restenosis; HbA1c: glycated hemoglobin A1c; LVEF: left ventricular ejection fraction; CTO: chronic total occlusion. 


\begin{tabular}{|c|c|c|c|c|c|c|}
\hline & $\begin{array}{l}\text { Unadjusted } \\
\text { OR }\end{array}$ & $\begin{array}{l}P \text { - } \\
\text { value }\end{array}$ & $\begin{array}{l}\text { Adjusted for } \\
\text { Model } 1 \text { OR }\end{array}$ & $\begin{array}{l}P \text { - } \\
\text { value }\end{array}$ & $\begin{array}{l}\text { Adjusted for } \\
\text { Model } 2 \text { OR }\end{array}$ & $\begin{array}{l}P \text { - } \\
\text { value }\end{array}$ \\
\hline $\begin{array}{l}\log _{2} \lg E \text { per } \\
\text { SD }\end{array}$ & $\begin{array}{l}2.008(1.613- \\
2.500)\end{array}$ & $<0.001$ & $\begin{array}{l}2.066(1.652- \\
2.583)\end{array}$ & $<0.001$ & $\begin{array}{l}1.989(1.567- \\
2.526)\end{array}$ & $<0.001$ \\
\hline IgE tertiles & $\begin{array}{l}1.831(1.431- \\
2.344)\end{array}$ & $<0.001$ & $\begin{array}{l}1.879(1.461- \\
2.417)\end{array}$ & $<0.001$ & $\begin{array}{l}1.773(1.355- \\
2.322)\end{array}$ & $<0.001$ \\
\hline $1 \mathrm{st}$ & Ref & & Ref & & Ref & \\
\hline $2 s t$ & $\begin{array}{l}1.658(1.019- \\
2.697)\end{array}$ & 0.042 & $\begin{array}{l}1.757(1.070- \\
2.884)\end{array}$ & 0.026 & $\begin{array}{l}1.646(0.971- \\
2.790)\end{array}$ & 0.064 \\
\hline 3st & $\begin{array}{l}3.346(2.043- \\
5.480)\end{array}$ & $<0.001$ & $\begin{array}{l}3.523(2.129- \\
5.829)\end{array}$ & $<0.001$ & $\begin{array}{l}3.137(1.831- \\
5.374)\end{array}$ & $<0.001$ \\
\hline $\begin{array}{l}\log _{2} \mathrm{CML} \\
\text { per SD }\end{array}$ & $\begin{array}{l}1.818(1.445- \\
2.287)\end{array}$ & $<0.001$ & $\begin{array}{l}1.824(1.444- \\
2.303)\end{array}$ & $<0.001$ & $\begin{array}{l}1.945(1.507- \\
2.509)\end{array}$ & $<0.001$ \\
\hline CML tertiles & $\begin{array}{l}1.617(1.268- \\
2.061)\end{array}$ & $<0.001$ & $\begin{array}{l}1.608(1.256- \\
2.060)\end{array}$ & $<0.001$ & $\begin{array}{l}1.744(1.333- \\
2.282)\end{array}$ & $<0.001$ \\
\hline $1 \mathrm{st}$ & Ref & & Ref & & Ref & \\
\hline $2 s t$ & $\begin{array}{l}1.334(0.824- \\
2.159)\end{array}$ & 0.241 & $\begin{array}{l}1.301(0.797- \\
2.124)\end{array}$ & 0.292 & $\begin{array}{l}1.543(0.902- \\
2.641)\end{array}$ & 0.113 \\
\hline $3 s t$ & $\begin{array}{l}2.605(1.604- \\
4.231)\end{array}$ & $<0.001$ & $\begin{array}{l}2.574(1.570- \\
4.221)\end{array}$ & $<0.001$ & $\begin{array}{l}3.026(1.768- \\
5.179)\end{array}$ & $<0.001$ \\
\hline
\end{tabular}

IgE and CML is analyzed as a log-transformed continuous variable, an ordinal variable divided according to tertiles of IgE or CML, and a categorical variable using the lowest tertile as reference. Model 1: adjusted for age, sex, body mass index, smoking, dyslipidemia, hypertension. Model 2: adjusted for age, sex, body mass index, smoking, dyslipidemia, hypertension, HbA1c, LVEF, statin use, number of diseased vessel, class B2/C lesion, bifurcation lesion, CTO lesion, stent diameter. As a continuous variable, OR is shown as per 1 SD (standard deviation). OR: odds ratio; HbA1c: glycated hemoglobin A1c; LVEF: left ventricular ejection fraction; СTO: chronic total occlusion

\section{Table 4 The predictive power of models for ISR}




\begin{tabular}{|c|c|c|c|c|c|c|c|}
\hline C-statistic & P-value & $\begin{array}{l}P_{\text {for }} \\
\text { comparison }\end{array}$ & $\begin{array}{l}\text { Categorical } \\
\text { NRI }\end{array}$ & P-value & IDI & P-value & \\
\hline $\begin{array}{l}\text { Established risk } \\
\text { factors }\end{array}$ & $\begin{array}{l}0.705 \\
(0.655- \\
0.755)\end{array}$ & $<0.001$ & Ref & Ref & Ref & & \\
\hline $\begin{array}{l}\text { Established risk } \\
\text { factors + IgE }\end{array}$ & $\begin{array}{l}0.759 \\
(0.713- \\
0.804)\end{array}$ & $<0.001$ & $<0.01$ & $\begin{array}{l}0.120 \\
(0.047- \\
0.194)\end{array}$ & $<0.01$ & $\begin{array}{l}0.074 \\
(0.049- \\
0.010)\end{array}$ & $<0.01$ \\
\hline $\begin{array}{l}\text { Established risk } \\
\text { factors + CML }\end{array}$ & $\begin{array}{l}0.748 \\
(0.701- \\
0.794)\end{array}$ & $<0.001$ & $<0.01$ & $\begin{array}{l}0.099 \\
(0.034- \\
0.163)\end{array}$ & $<0.01$ & $\begin{array}{l}0.062 \\
(0.038- \\
0.086)\end{array}$ & $<0.01$ \\
\hline
\end{tabular}

ISR: in-stent restenosis; NRI: net reclassification improvement; IDI: integrated discrimination improvement

\section{Figures}

\section{Consecutive T2DM CAD patients with elective PCl $(2017 / 01-2020 / 12, n=606)$}

\section{Excluded $(n=175)$}

$\sim$ Acute coronary syndrome $(n=133)$

$\sim$ Famlial hypercholesterolemia $(n=5)$

$\sim$ Malignant tumor $(\mathrm{n}=6)$

$\sim$ Renal failure requiring hemodialysis $(n=4)$

$\sim$ CABG history $(=27)$

\section{T2DM patients}

T2DM + ISR $(n=196)$
Excluded $(n=15)$

$\sim$ Asthma $(\mathrm{n}=5)$

$\sim$ Autoimmune disease $(n=4)$

$\sim$ Rheumatic heart disease $(n=6)$

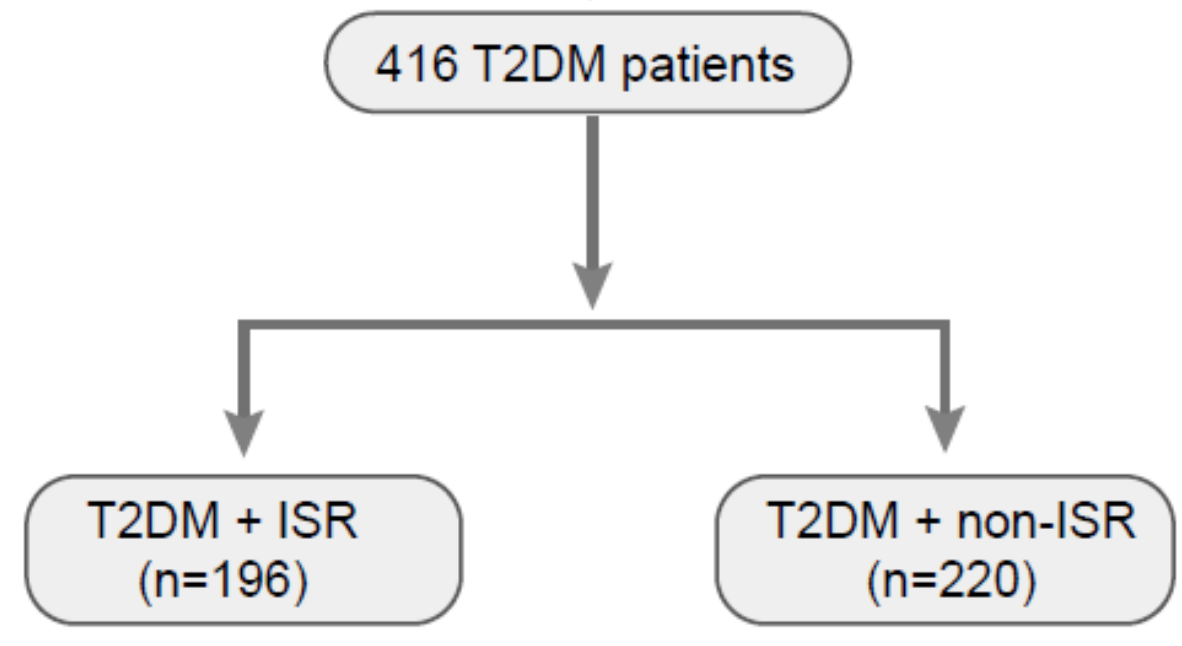


Figure 1

Flow chart of recruitment procedure. T2DM: type 2 diabetes mellitus; CAD: coronary artery disease; PCl: percutaneous coronary intervention; CABG: coronary artery bypass grafting; ISR: in-stent restenosis

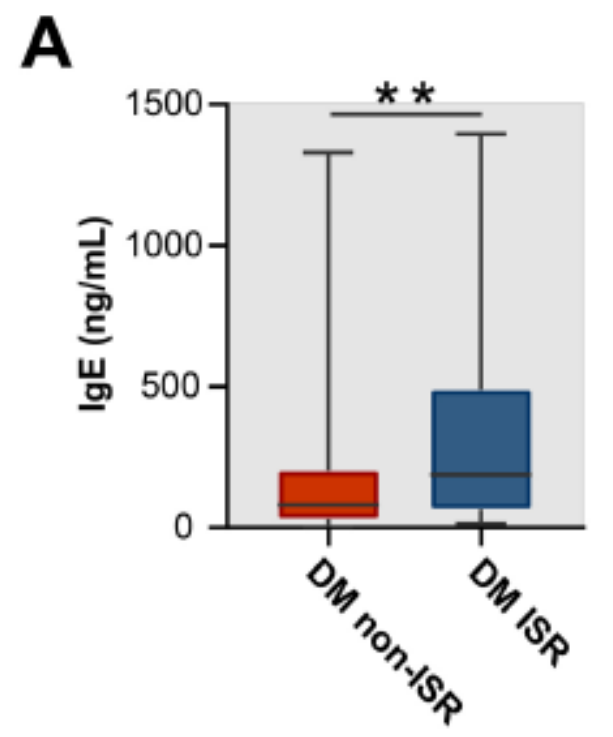

B

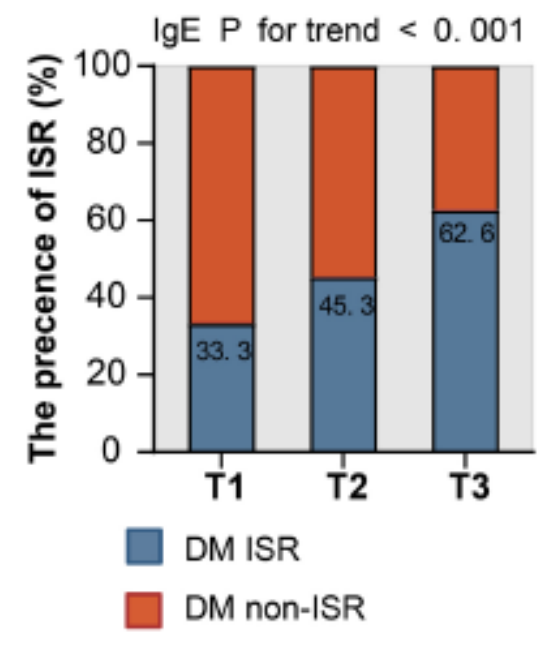

C

D

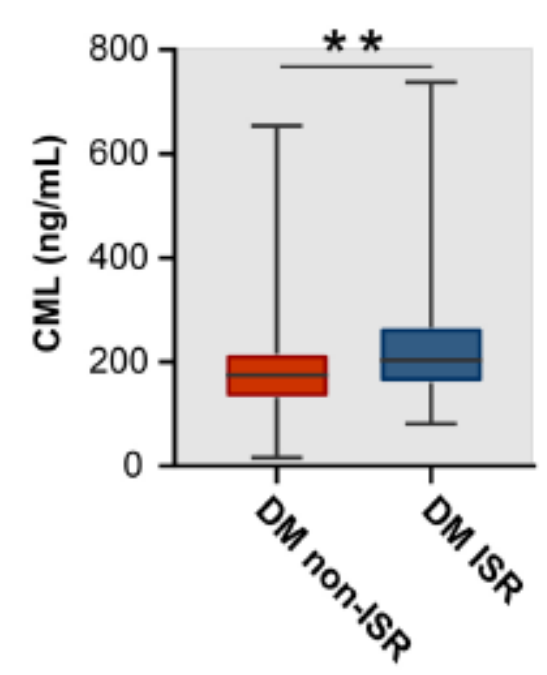

CML $\mathrm{P}$ for trend $<0.001$

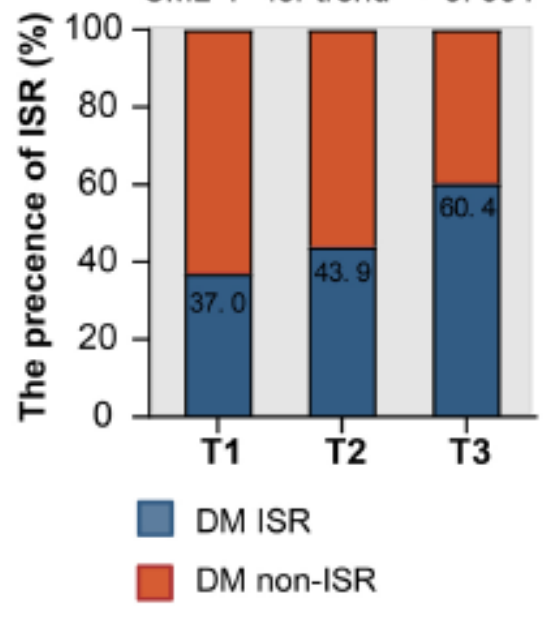

Figure 2

Association of serum IgE and CML levels with ISR in T2DM patients. Comparison of serum IgE $(A)$ and CML (C) levels between patients with and without ISR in T2DM patients. In-stent restenosis across the tertiles of IgE (B) and CML (D). ISR: in-stent restenosis; T2DM: type 2 diabetes mellitus. ${ }^{*} \mathrm{P}<0.01$ 
A

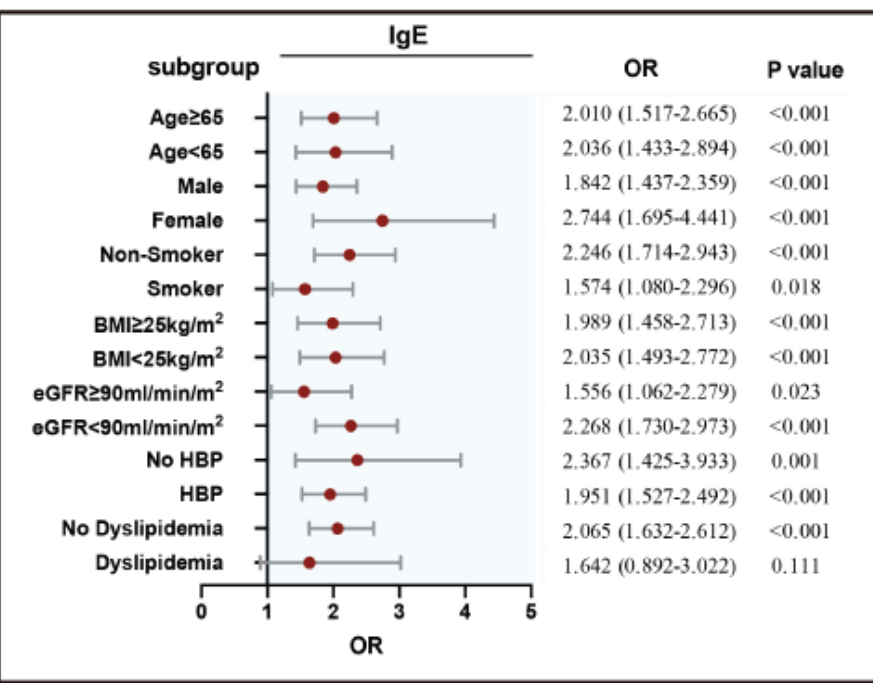

B

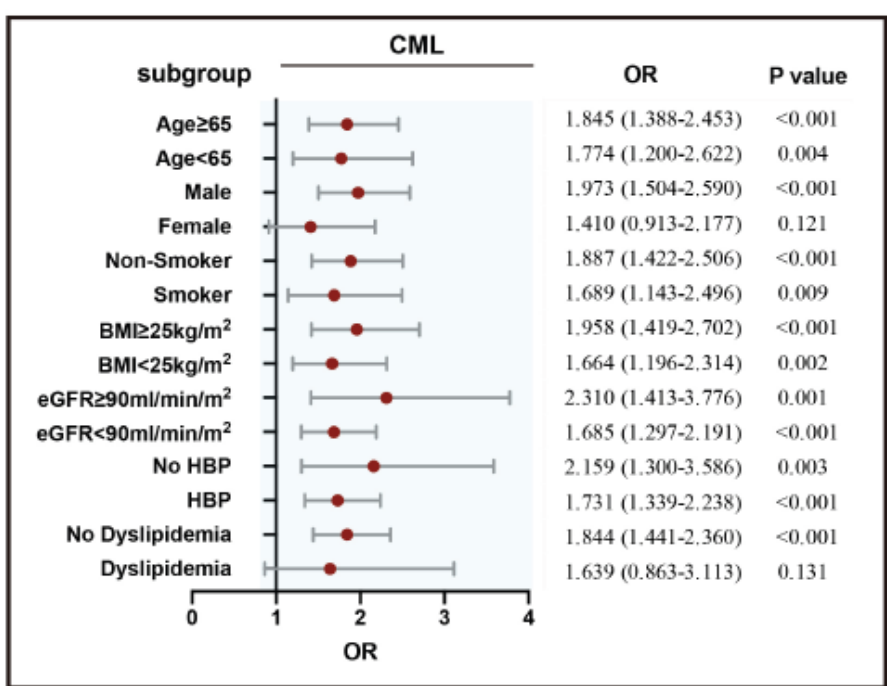

Figure 3

Forrest plots (unadjusted) to analyze the predictive value of $\operatorname{IgE}(\mathrm{A})$ or CML (B) for ISR in different subgroups of T2DM patients. IgE or CML was included as a log-transformed continuous variable. BMI: body mass index; eGFR: estimated glomerular filtration rate; HBP: high blood pressure; ISR: in-stent restenosis; T2DM: type 2 diabetes mellitus

A

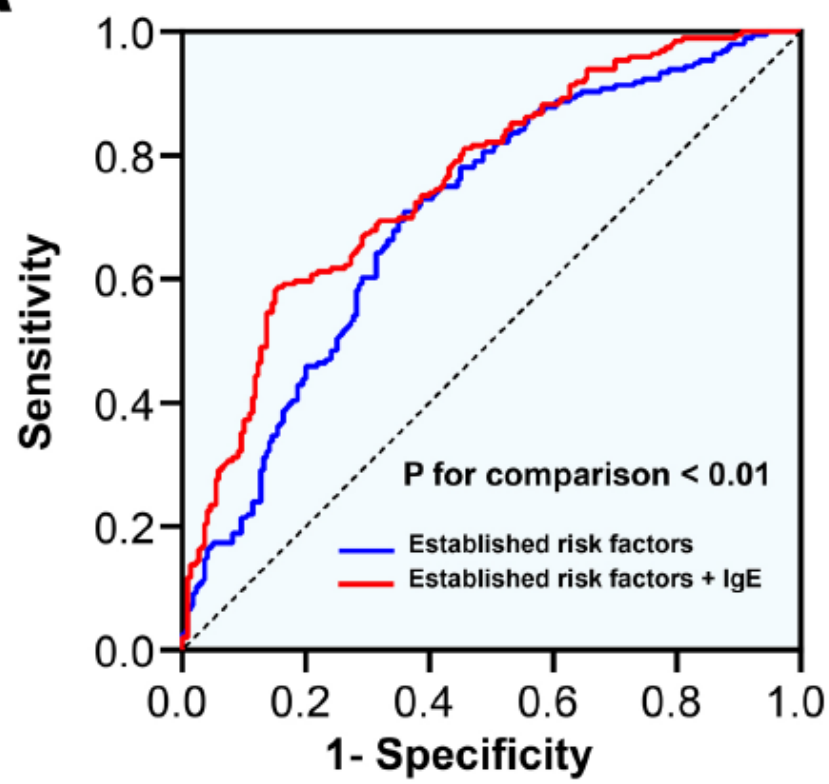

B

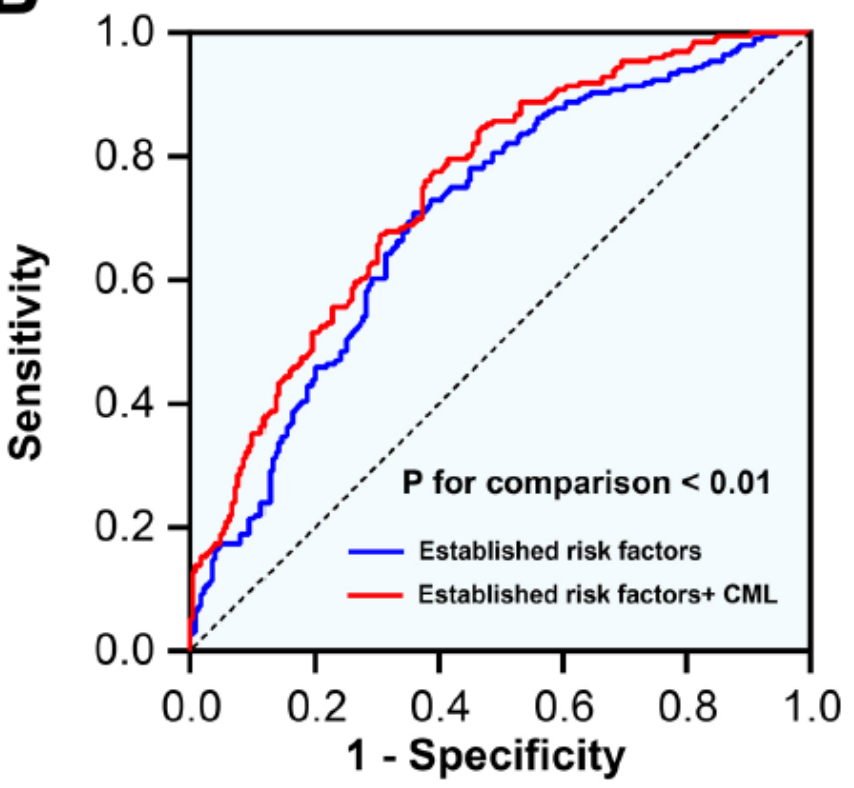

Figure 4

Receiver operating characteristic curve analysis between models to verify the predictive values of IgE (A) and $\mathrm{CML}(\mathrm{B})$. 


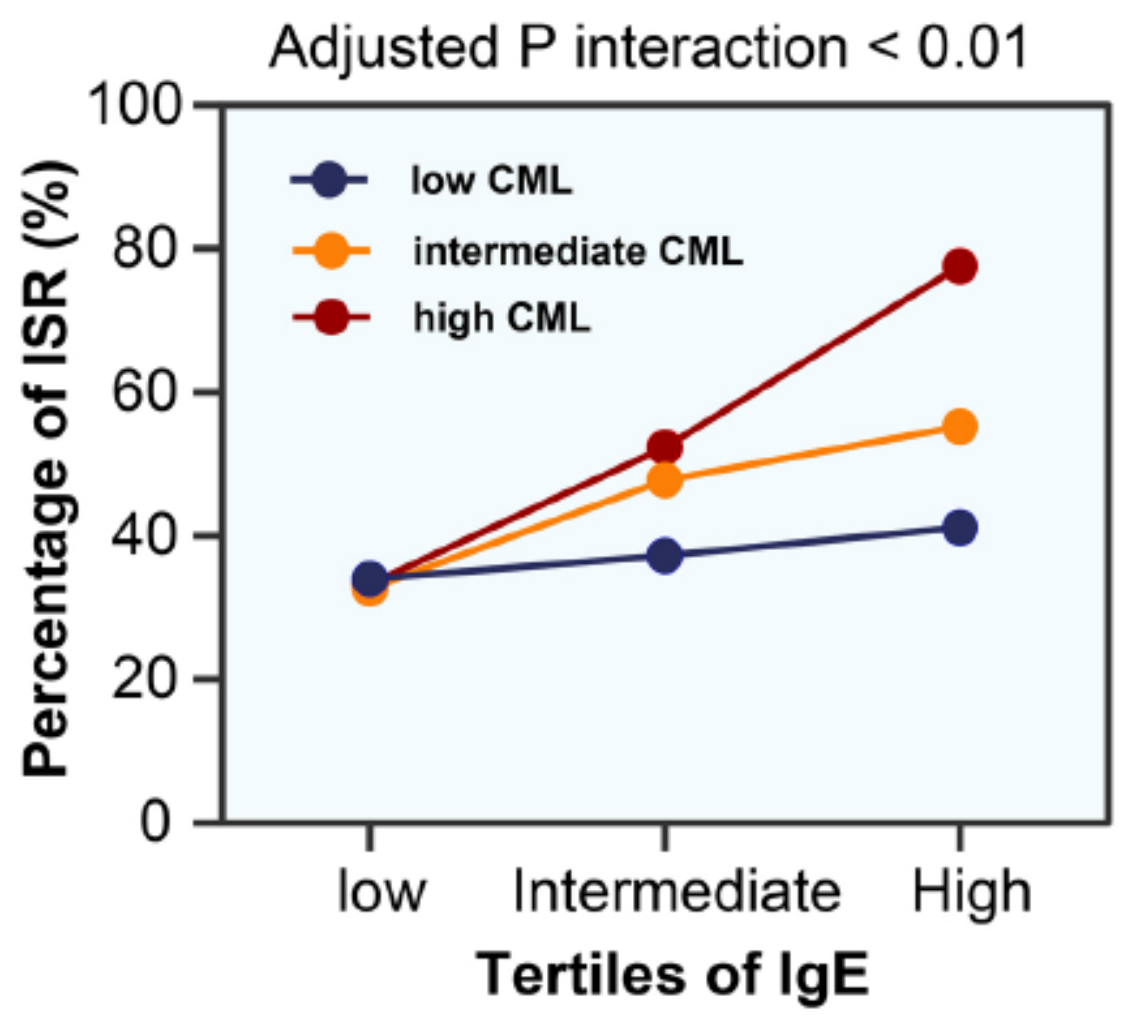

Figure 5

Percentage of ISR in relation to interaction between IgE and CML. ISR: in-stent restenosis. 
A

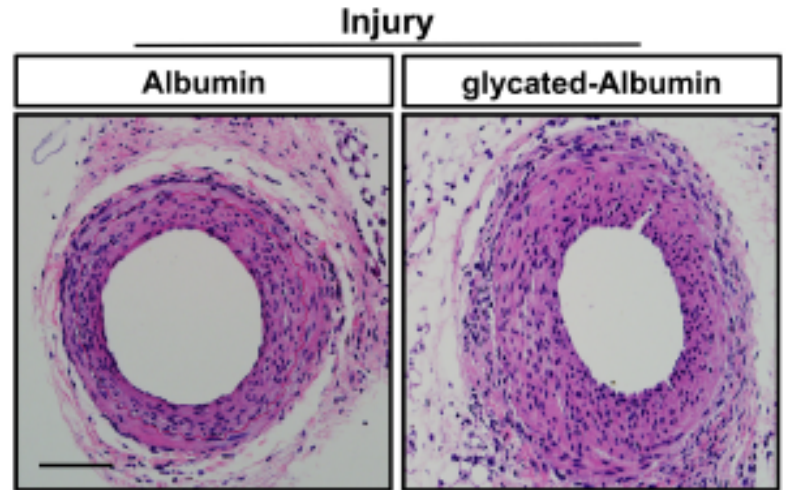

B

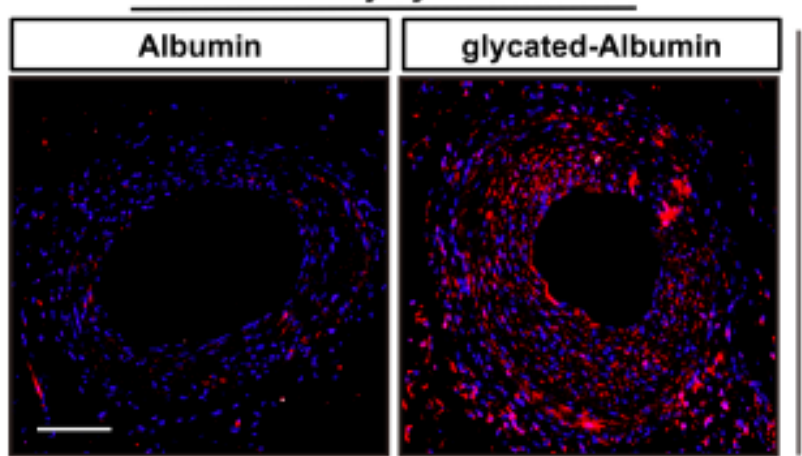

C

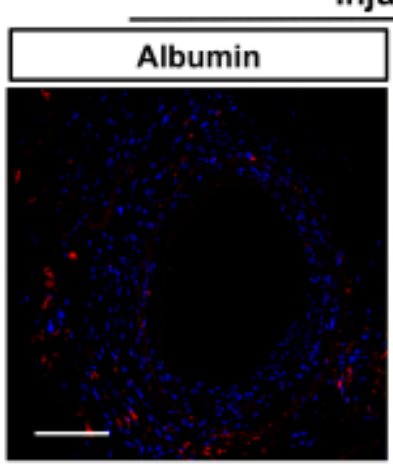

Injury

\section{glycated-Albumin}

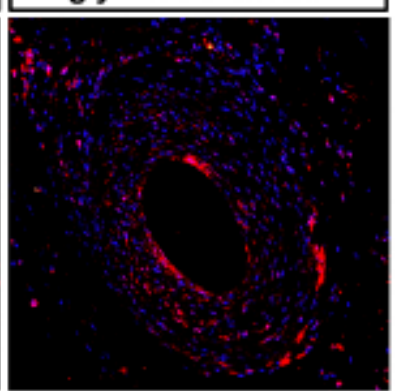

D

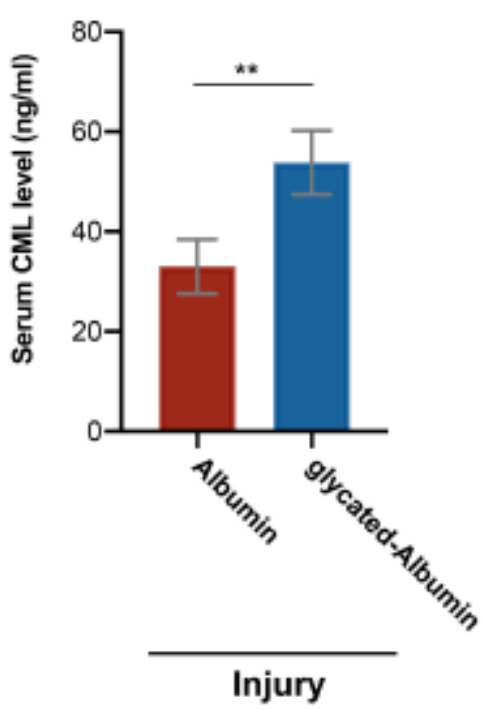

$\mathbf{E}$

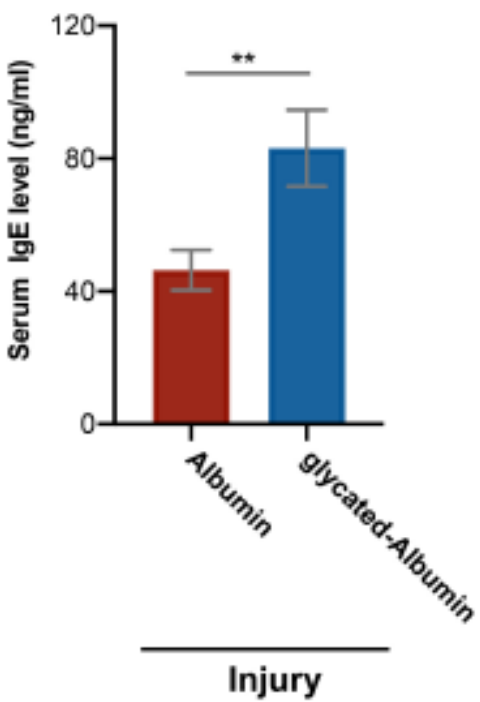

Figure 6

Glycated albumin induced greater neointimal hyperplasia and elevated CML and IgE in mice. The mouse arteries were harvested 28 days after injury. Representative images of H\&E staining (A) and immunofluorescent staining for CML (red) (B) and IgE (red) (C) of wire-injured femoral artery sections in mice receiving albumin and glycated albumin injection. Serum $\mathrm{CML}(\mathrm{D})$ and $\lg E(\mathrm{E})$ levels in mice. ${ }^{\star *} \mathrm{P}<$ $0.01, n=6$ each group. Scale bar: $100 \mu \mathrm{m}$ 